\title{
Cost-Effectiveness of Betrixaban Compared with Enoxaparin for Venous Thromboembolism Prophylaxis in Nonsurgical Patients with Acute Medical IIIness in the United States
}

\author{
Holly Guy ${ }^{1} \cdot$ Vicki Laskier $^{1} \cdot$ Mark Fisher $^{1} \cdot$ W. Richey Neuman ${ }^{2} \cdot$ Iwona Bucior $^{2} \cdot$ Steven Deitelzweig ${ }^{3}$. \\ Alexander T. Cohen ${ }^{4}$
}

Published online: 21 December 2018

(c) The Author(s) 2018

\begin{abstract}
Background Studies show that the risk of venous thromboembolism (VTE) continues post-discharge in nonsurgical patients with acute medical illness. Betrixaban is the first anticoagulant approved in the United States (US) for VTE prophylaxis extending beyond hospitalization.

Objective The aim was to establish whether betrixaban for VTE prophylaxis in nonsurgical patients with acute medical illness at risk of VTE in the US is cost-effective compared with enoxaparin.

Methods A cost-effectiveness analysis was conducted, estimating the cost per quality-adjusted life-year (QALY) gained with betrixaban (35-42 days) compared with enoxaparin (6-14 days) from a US payer perspective over a lifetime horizon. A decision tree (DT) estimated primary VTE events, thrombotic events, and treatment complications in the first 3 months based on data from the phase III Acute Medically Ill VTE Prevention with Extended Duration Betrixaban study. A Markov model estimated recurrent events and long-term complication risks from published literature. EuroQoL-5 Dimensions utility data and costs inflated to 2017 US dollars (US\$) were from published literature. Results were discounted at 3.0\% per annum. Deterministic and probabilistic sensitivity analyses explored uncertainty.

Results Betrixaban dominated enoxaparin, with savings of US\$784 and increased QALYs of 0.017 per patient. In addition, betrixaban dominated enoxaparin across all sensitivity analyses, but was most sensitive to utilities and DT probabilities. Furthermore, probabilistic sensitivity analysis found that betrixaban was more cost-effective than enoxaparin at all willingness-to-pay thresholds. Conclusion Betrixaban can be considered cost-effective for nonsurgical patients with acute medical illness at risk of VTE, requiring longer VTE prophylaxis from hospitalization through post-discharge.
\end{abstract}

Electronic supplementary material The online version of this article (https://doi.org/10.1007/s40273-018-0757-8) contains supplementary material, which is available to authorized users.

Holly Guy

holly.guy@fiecon.com

1 FIECON Ltd, 3 College Yard, Lower Dagnall Street, Hertfordshire, St Albans AL3 4PA, UK

2 Portola Pharmaceuticals, Inc, South San Francisco, CA, USA

3 Ochsner Clinic Foundation and The University of Queensland School of Medicine, Ochsner Clinical School, New Orleans, LA, USA

4 Guy's and St, Thomas' Hospitals, London, UK

\section{Key Points for Decision Makers}

Prophylaxis of venous thromboembolism (VTE) from hospitalization through post-discharge is a new option for acute medically ill patients at high risk of thromboembolic events.

In the US, a 35-42-day regimen with betrixaban, from hospitalization through post-hospital-discharge, was found to accrue more quality-adjusted life-years (QALYs) and less costs compared with a 6-14-day prophylaxis with enoxaparin, due to a reduced incidence of thromboembolic events and lower associated costs, for nonsurgical patients with acute medical illness at risk of VTE.

Betrixaban dominated enoxaparin, with 0.017 additional QALYs accrued and cost savings of US\$784 per patient. 


\section{Introduction}

Venous thromboembolism (VTE) is a life-threatening condition and a leading but preventable cause of morbidity and mortality [1-3]. VTE typically originates as a deep-vein thrombosis (DVT), which can travel to the lungs causing a pulmonary embolism (PE), potentially causing sudden death. Surviving patients may require intensive care, and recovery can take several weeks or months. Patients with VTE are also at risk for recurrent VTE and other debilitating complications, including post-thrombotic syndrome (PTS) or chronic thromboembolic pulmonary hypertension (CTEPH) $[4,5]$.

Short-term, in-hospital subcutaneous VTE prophylaxis for nonsurgical patients includes unfractionated heparin (UFH), fondaparinux sodium, and low molecular weight heparins (LMWHs), e.g., enoxaparin [6, 7]. However, despite extensive use of in-hospital prophylaxis, VTE incidence remains high in at-risk patients [8]. With up to 800,000 VTE events and 30,000 VTE-related deaths occurring annually in the US [9] and less than 50\% of patients estimated to have received VTE prophylaxis [10], greater uptake of VTE prophylaxis both in-hospital and post-discharge could reduce VTE morbidity and mortality. Studies have shown that the risk of VTE and VTE-related death associated with hospitalization persists for 1-3 months post-hospital discharge in high-risk acute medically ill patients [3, 10-15]. Approximately half of VTE events occur following discontinuation of in-hospital prophylaxis and after hospital discharge in at-risk patients. Therefore, previous studies investigated VTE prophylaxis through post-discharge compared with in-hospital prophylaxis, but investigated anticoagulants were associated with significantly increased major bleeding (MB), outweighing the net benefit of longer VTE prophylaxis [16-18]. Therefore, VTE prophylaxis extending through post-discharge is not currently recommended in this population, limiting the guidance on improving VTE prevention in acute medically ill patients at high risk of VTE $[10,14,15,19,20]$.

Betrixaban is a direct oral anticoagulant for VTE prophylaxis that is a potent and specific inhibitor of human factor $\mathrm{Xa}$, a key component in the formation of blood clots. Studies have highlighted several pharmacological properties that make betrixaban appropriate to treat the acute medically ill population: effective half-life (19-27 h) permitting once-daily dosing, low peak-to-trough concentration ratio, low renal clearance, and lack of cytochrome P450 (CYP450) enzyme interactions [21, 22]. These properties provide consistent anticoagulation over $24 \mathrm{~h}$, without needing dose adjustment for patients with mild or moderate renal impairment (patients with severe renal impairment or receiving P-glycoprotein inhibitors require dose adjustment) and a low propensity for drug-drug interactions on the CYP450 reaction pathway.
The average length of hospital stay for medical patients fell from 9.0 to 5.1 days between 1990 and 2015, augmenting the need for VTE prophylaxis through post-hospital discharge [23-26]. Approved in June 2017 in the US, by the Food and Drug Administration (FDA), betrixaban is indicated for VTE prophylaxis in adult patients hospitalized for an acute medical illness at risk of thromboembolic complications due to moderate or severe restricted mobility and other VTE risk factors [27, 28]. The pivotal phase III Acute Medically Ill VTE Prevention with Extended Duration Betrixaban (APEX) study (NCT01583218) (Table 1) demonstrated that 35-42-day prophylaxis with betrixaban reduced VTE occurrence in acute medically ill nonsurgical patients compared with 6-14-day prophylaxis with enoxaparin, without significant increase in MB [29, 30]. Online Resource 1 (see the electronic supplementary material) presents the baseline characteristics of the APEX population.

Net clinical benefit was defined as the composite of the primary efficacy and principal safety endpoints in APEX [30]. In the overall efficacy population, net clinical benefit occurred in $5.8 \%$ and $7.3 \%$ of the betrixaban and enoxaparin cohorts, respectively; favorable for betrixaban compared with enoxaparin ( $p=0.01$ ) [30-32]. However, cost-effectiveness was not investigated.

Therefore, this study aimed to establish the cost-effectiveness of betrixaban compared with enoxaparin for VTE prophylaxis in nonsurgical patients with acute medical illness at risk of VTE in the US.

\section{Methods}

A cost-effectiveness model was developed in Microsoft ${ }^{\circledR}$ Excel 2010 (Redmond, WA, US) to estimate the expected costs and outcomes for VTE prophylaxis with betrixaban (35-42 days) compared with enoxaparin (6-14 days) in nonsurgical patients with acute medical illness at risk of VTE. The primary outcome was the incremental cost-effectiveness ratio, expressed as cost per quality-adjusted life-year (QALY) gained.

Occurrence rates of VTE events and acute complications were clinical outcomes assessed in the APEX trial and were used in this cost-effectiveness analysis. A systematic literature review (SLR) (Online Resource 2, see the electronic supplementary material) was conducted to inform the model structure, costs, quality-of-life (QoL), and clinical inputs, where APEX trial data were not available. The SLR revealed a paucity of evidence for VTE prophylaxis through postdischarge, with previous studies reporting increased risk of MB with prophylaxis through post-discharge compared with in-hospital and US guidelines currently recommending inhospital VTE prophylaxis [16-20]. 
Table 1 APEX trial characteristics

\begin{tabular}{|c|c|}
\hline Study design & Phase III, large $(n=7513)$, international, multicenter, double-blind, RCT \\
\hline Population & $\begin{array}{l}\text { Patients } 40 \text { years of age or older, who had been hospitalized for less than } 96 \mathrm{~h} \text { for a specified acute medical illness } \\
\text { (heart failure, respiratory failure, infectious disease, rheumatic disease, or IS), and had reduced mobility and spe- } \\
\text { cific risk factors for VTE } \\
\text { Efficacy analyses were performed based on the mITT population (patients who received at least one dose of study } \\
\text { drug and completed a follow-up assessment for at least one efficacy outcome) }\end{array}$ \\
\hline Intervention & $\begin{array}{l}\text { Betrixaban, oral, at a loading dose of } 160 \mathrm{mg} \text { for the first dose and then } 80 \mathrm{mg} \text { once daily for } 35-42 \text { days (plus SC } \\
\text { enoxaparin placebo for 6-14 days) } \\
\text { Patients with severe renal impairment or who were receiving a concomitant P-glycoprotein inhibitor received a half } \\
\text { dose of the study medication: a loading dose of } 80 \mathrm{mg} \text { for the first dose and then } 40 \mathrm{mg} \text { once daily for 35-42 days } \\
\text { (plus SC enoxaparin placebo for 6-14 days) }\end{array}$ \\
\hline Comparator & $\begin{array}{l}\text { Enoxaparin SC at a dosage of } 40 \mathrm{mg} \text { once daily for 6-14 days (plus oral betrixaban placebo for } 35-42 \text { days) } \\
\text { Patients with severe renal impairment received a half dose of this study medication: } 20 \mathrm{mg} \text { once daily for } 6-14 \text { days } \\
\text { (plus oral betrixaban placebo for } 35-42 \text { days) }\end{array}$ \\
\hline Method of randomization & $\begin{array}{l}\text { Patients were randomized } 1: 1 \text { to receive betrixaban or enoxaparin once daily using random permutated blocks within } \\
\text { geographic region, stratified by dosing and entry criteria, and an interactive voice-response system }\end{array}$ \\
\hline Efficacy outcomes & $\begin{array}{l}\text { The primary outcome was a composite of ADVT between day } 32 \text { and day 47, or SDVT, PE, or VTE-related death } \\
\text { through day } 42 \\
\text { The two major secondary outcomes were a composite of symptomatic VTE through day } 42 \text {, and a composite of } \\
\text { ADVT between day } 32 \text { and day } 47 \text {, SDVT, non-fatal PE, or death from any cause through day } 42\end{array}$ \\
\hline Safety outcomes & The principal safety endpoint was occurrence of MB at any point until 7 days after study drug discontinuation \\
\hline
\end{tabular}

$A P E X$ Acute Medically Ill VTE Prevention with Extended Duration Betrixaban, $A D V T$ asymptomatic deep-vein thrombosis, $I S$ ischemic stroke, $M B$ major bleeding, $m I T T$ modified intent-to-treat, $P E$ pulmonary embolism, $R C T$ randomized controlled trial, $S C$ subcutaneous, $S D V T$ symptomatic deep-vein thrombosis, VTE venous thromboembolism

\subsection{Target Population}

Betrixaban's approved FDA label was informed by the eligible population for the APEX study, also used by the model: adults hospitalized for an acute medical illness who are at risk for thromboembolic complications due to moderate or severe restricted mobility and are aged $\geq 75$ years, aged 60-74 years with D-dimer $\geq 2 \times$ upper limit of normal (ULN), or aged 40-59 years with D-dimer $\geq 2 \times$ ULN and a history of either VTE or cancer [27, 28, 30].

A subgroup analysis was conducted using betrixaban $80 \mathrm{mg}$ and enoxaparin $40 \mathrm{mg}$ data only: data from patients with severe renal impairment in both study arms or patients who received P-glycoprotein inhibitors in the betrixaban arm who received a reduced study intervention dose were excluded, to investigate the impact of dose size on results.

\subsection{Interventions}

The interventions entering the model were betrixaban and enoxaparin. In the APEX study, patients were randomized $1: 1$ to receive oral betrixaban $80 \mathrm{mg}$ once daily (with an initial loading dose of $160 \mathrm{mg}$ then $80 \mathrm{mg}$ once daily for 35-42 days) or enoxaparin $40 \mathrm{mg}$ subcutaneously once daily for $10 \pm 4$ days [30]. Actual treatment duration in the model ( 36 days betrixaban, 9 days enoxaparin) was based on the median treatment duration in APEX [30]. Patients with severe renal impairment in both study arms or patients who received P-glycoprotein inhibitors in the betrixaban arm received $50 \%$ of the study dose $[28,30]$.

\subsection{Model Structure}

A decision analytic model was constructed with a decisiontree component (evaluating short-term costs and outcomes of prophylaxis) followed by a Markov model component (evaluating long-term costs and outcomes post-prophylaxis). This structure aligns with several published US-perspective VTE prophylaxis cost-effectiveness studies, whose model structures consist of a decision tree, Markov model, or combination of both [33-38]. Model health states were selected to capture events that impact VTE at-risk patients requiring prophylaxis, based on events captured in previous studies and outcomes observed in the APEX study [30].

Two 1000-patient cohorts entered the model, receiving either betrixaban or enoxaparin. A decision-tree structure was used to capture VTE events, myocardial infarction (MI), ischemic stroke (IS), pharmacological prophylaxis complications (intracranial hemorrhage [ICH], MB, clinically relevant non-MB, heparin-induced thrombocytopenia [HIT], and HIT with thrombosis [HITT]), and death in the 3 months following initiation of prophylaxis (Fig. 1). HIT and HITT are potentially life-threatening complications in VTE at-risk patients [33-35, 39]. Treatment involves discontinuation of heparin-anticoagulants and initiation of non-heparin anticoagulation [39].

Two sub-trees captured pharmacological prophylaxis complications and death following a VTE (Online Resource 
3, see the supplementary electronic material) or MI event (Online Resource 4). A third sub-tree captured severity of IS and death following IS (Online Resource 5, see the supplementary electronic material). The first two sub-trees carried the additional risk of complications that arise with increased anticoagulation therapy for VTE and MI events. Following an IS event (sub-tree 3), US guidelines recommend aspirin therapy over anticoagulation, so patients are modelled to either survive or enter the non-VTE-related death health state and are not considered to be at risk of additional anticoagulation complications [40].

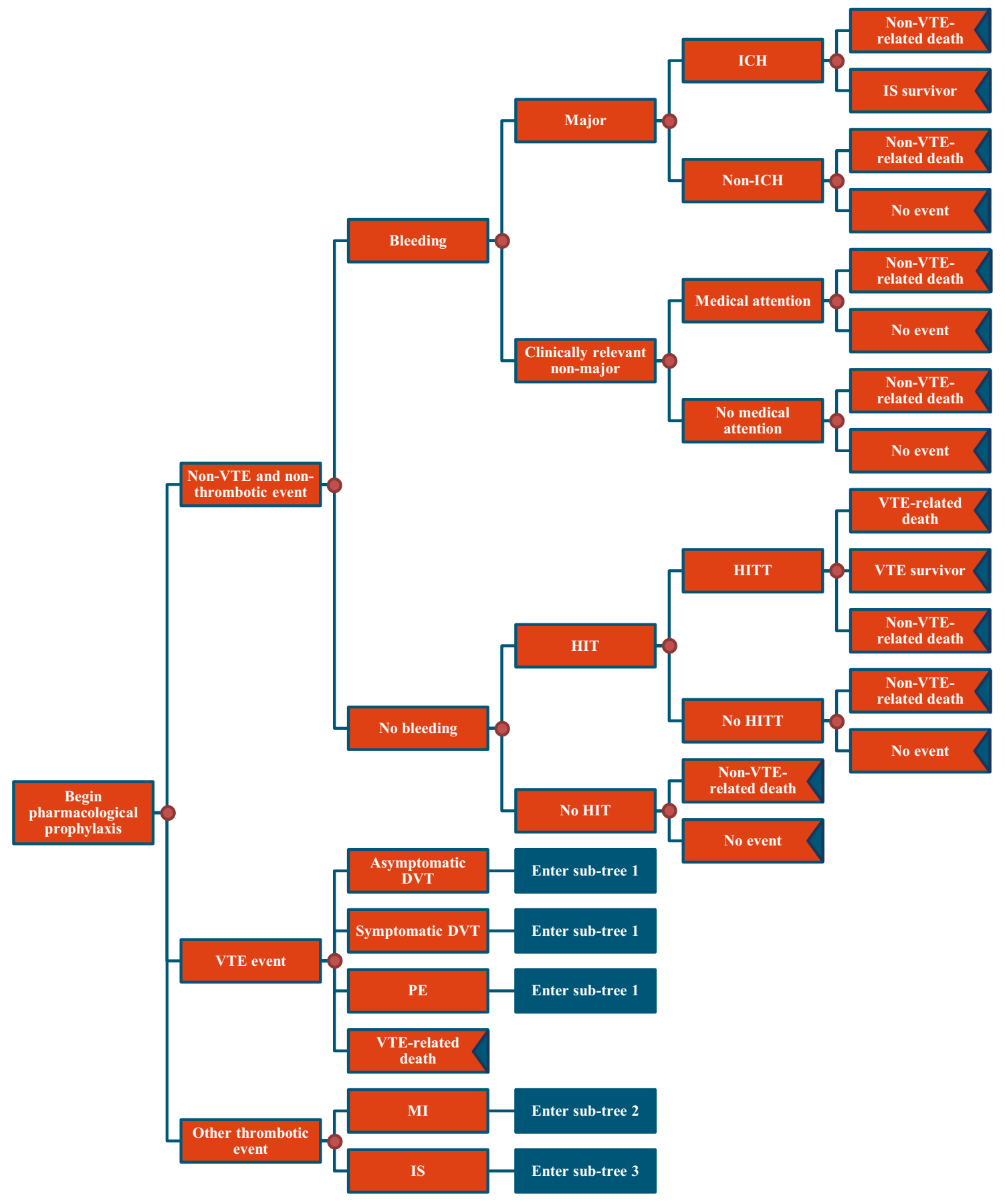

Fig. 1 Initial decision tree. DVT deep-vein thrombosis, HIT heparininduced thrombocytopenia, HITT heparin-induced thrombocytopenia with thrombosis, $I C H$ intracranial hemorrhage, $I S$ ischemic stroke, $M I$

myocardial infarction, $P E$ pulmonary embolism, VTE venous thromboembolism 
The severity of IS was defined according to the modified Rankin scale; scores of 0-2, 3-4, and 5-6 were classified as mild, moderate, and severe, respectively. Within the subtrees, a "VTE-related death" was only possible following a VTE event or HITT event and a "non-VTE-related death" included death by other causes. If a patient survived an ICH, they transitioned into the "IS survivor" health state in the model to maintain model simplicity; it was assumed that the QoL and further costs would be similar for ICH survivors and IS survivors. Note that if a patient enters "IS survivor" state after an ICH event, they are not an "IS survivor", but are modelled to experience similar impact on QoL and costs. This is a conservative assumption since ICH survivors incur more costs and have reduced survival compared with IS survivors. It was reported that over 4 years, costs of US $\$ 38,023$ and US $\$ 48,327$ were accrued for survivors of ICH and subarachnoid hemorrhage, a subtype of ICH, whereas IS survivors accrue US\$39,396 [41]. Likewise, 1-year fatality was $58 \%$ for ICH, compared with consistently below $53 \%$ for IS $[42,43]$.

After 3 months, patients entered a Markov model with 3-monthly cycles based on their end state in the decision tree (Fig. 2). Patients could reside in one of the following health states: no event, VTE survivor, MI survivor, IS survivor, VTE-related death, and non-VTE-related death. Following a primary event, VTE, MI, and IS survivors were at risk of recurrent or fatal events, with VTE survivors also at risk of PTS and CTEPH. These event probabilities were sourced from published literature.

Costs and QALYs were calculated based on the occurrence of events in the decision tree, and then for each Markov cycle, based on the patient distribution across all health states and probabilities of events relevant to health states. These accumulate over the time horizon, giving the total costs and QALYs.

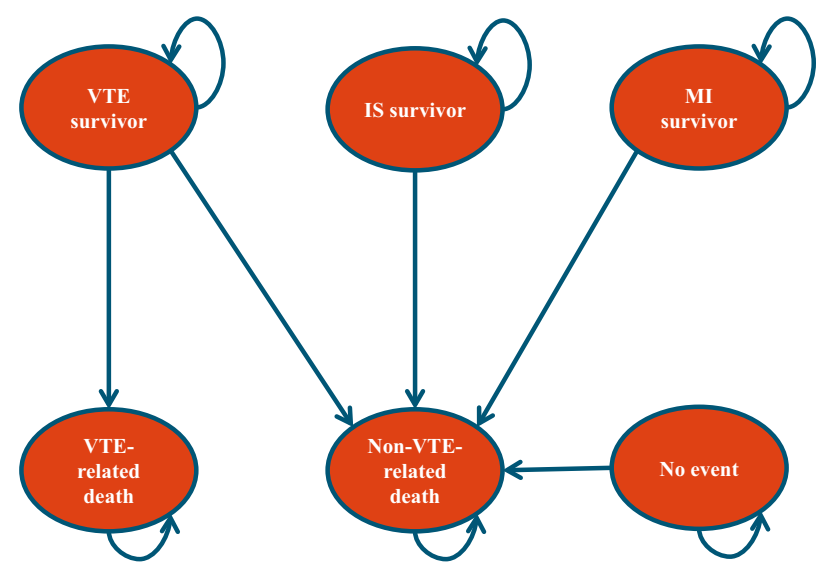

Fig. 2 Markov model structure. $I S$ ischemic stroke, $M I$ myocardial infarction, VTE venous thromboembolism

\subsection{Time Horizon, Discounting, and Perspective}

To capture the ongoing risk of recurrent or fatal events and VTE-related complications, a lifetime horizon was used in the model ( 25 years). This was based on the mean age of patients in the APEX study (76 years), and assumed that no patients survive beyond 100 years [30]. Costs and outcomes were discounted at 3\% per annum in line with World Health Organization guidelines [44]. The analysis was conducted from the US payer perspective.

\subsection{Model Inputs}

\subsubsection{Clinical Parameters}

The APEX study directly informed decision-tree event occurrence and patient demographics at baseline (age 76 years, sex $46 \%$ male) as it is the only randomized controlled trial (RCT) directly comparing betrixaban with enoxaparin [30]. Table 2 shows the number of patients in each Markov model health state post-decision tree. Online Resource 6 (see the supplementary electronic material) displays the percentages of patients who experienced an asymptomatic DVT, symptomatic DVT, or PE in the decision tree, from APEX patient-level data, and Markov model event probabilities, from published literature.

For the decision tree, patient flow was sourced from APEX patient-level data through to study end at day 77 . Since there were no HIT or HITT cases during APEX, the associated probabilities were zero. The percentage of patients reaching each health state at the Markov model entry was determined by summing the percentages of a patient traversing each appropriate tree path. Since the incidence rate of symptomatic events plateaued between day 42 and 77 for betrixaban, it was conservatively assumed that patients experienced no more primary events after day 77 $[31,45]$. Therefore, patients remained in the resultant health state until entry into the Markov model.

Table 2 Number and percentage of patients in each health state ${ }^{a}$ following the decision tree

\begin{tabular}{lcc}
\hline Health state & Betrixaban, $n(\%)$ & Enoxaparin, $n(\%)$ \\
\hline No event & $901(90.14)$ & $879(87.93)$ \\
VTE survivor & $40(3.95)$ & $54(5.40)$ \\
Myocardial infarction & $2(0.16)$ & $3(0.32)$ \\
$\quad$ survivor & & \\
Ischemic stroke survivor & $2(0.19)$ & $6(0.65)$ \\
VTE-related death & $4(0.40)$ & $7(0.70)$ \\
Non-VTE-related death & $52(5.16)$ & $50(5.00)$ \\
\hline
\end{tabular}

$V T E$ venous thromboembolism

${ }^{\text {a }}$ Number of patients in each health state is scaled to the 1000-person cohort per treatment arm 
Recurrent event probabilities (Online Resource 7, see the supplementary electronic material) in the Markov model were assumed to be the same regardless of pharmacological prophylaxis received. Once patients experienced either PTS or CTEPH, they were assumed to experience the complication for life, except in cases of successful CTEPH surgery. Probabilities of death were based on all-cause mortality probabilities adjusted for decreased life expectancy following hospitalization for acute medical illnesses, using a hazard ratio of 1.367 , derived from a study reporting decreased life expectancy following heart failure, one of the possible eligibility criteria for APEX [30, 46, 47].

\subsubsection{Resource Utilization and Cost Inputs}

Direct healthcare costs were informed by published literature. Where required, costs were inflated to 2017 US dollars using the Consumer Price Index medical inflation rates for the US [48]. Model costs and resource use are summarized in Online Resource 8 (see the supplementary electronic material).

Prophylaxis costs were aligned with the duration and dosing as per the APEX study, with patients hospitalized for the first 5 days of treatment and remaining doses being selfadministered at home [30]. Dosing regimens included 37 doses of betrixaban (two loading and 35 maintenance; $80 \mathrm{mg}$ as standard, $40 \mathrm{mg}$ for those with severe renal impairment or for those receiving P-glycoprotein inhibitors) and nine doses of enoxaparin (40 mg as standard, $20 \mathrm{mg}$ for those with severe renal impairment).

Since enoxaparin is administered subcutaneously, it was assumed that a nurse would administer treatment in hospital. Though in APEX all doses were received during hospitalization, the model conservatively assumes a mean stay of 5 days so that patients self-administer the final doses, despite a nurse typically administering all doses. Costs and resource use for in-hospital blood-count monitoring of enoxaparin patients were also included. Mean treatment costs per patient for 36-day betrixaban and 9-day enoxaparin were US\$525.00 and US\$232.58, respectively.

Costs associated with the management of pharmacological prophylaxis complications captured in the decision tree included bleeding (ICH, non-ICH major, and clinically relevant non-major requiring medical attention), HIT, and HITT. Management costs for VTE events and other thrombotic events in the decision tree were incurred for DVT, PE, and VTE-related death, and IS and MI. Corresponding management costs in the Markov model included costs for recurrent VTE, VTE-related death, and VTE complications (PTS and CTEPH), and recurrent IS and MI. For each event, costs were applied instantaneously to appropriate patients in the decision tree and were applied as they occur in the Markov model.
Finally, VTE survivors received follow-up costs for complications (CTEPH and PTS), applied on a by-cycle basis for patients who developed either condition and remained alive. Additionally, IS and MI survivors incurred lifelong follow-up costs applied from day 77 until decision-tree exit and every cycle in the Markov model until death.

\subsubsection{Utilities}

Since QoL data were not collected in APEX, utility and disutility data were sourced from published literature, using EuroQol-5 Dimensions utility data where possible. Online Resource 9 and Online Resource 10 (see the supplementary electronic material) display the utilities and disutilities applied within the model. A "hospitalized medically ill" utility was applied for the first 5 days in the decision tree, as required for betrixaban eligibility [38]. Following hospitalization, a "no event" utility was applied to patients who experienced no event [38]. The utility of a VTE survivor was approximated by subtracting the weighted average of PE and DVT survivors (symptomatic and asymptomatic) disutilities from the "no event" utility [49, 50]. Similarly, the utilities of MI and IS survivors were estimated by subtracting the MI and IS disutility from the "no event" utility, respectively [51, 52]. Since IS was stratified by severity, the disutility was weighted according to the number of events in the decision tree.

Direct disutility event data were used where reported, and were otherwise obtained by subtracting event utility from baseline utility in the reported study [51-54].

\subsubsection{Sensitivity Analyses}

Deterministic sensitivity analyses consisted of scenario analyses and one-way sensitivity analysis (OWSA) to test structural and parameter uncertainty in the model. Table 3 details the scenario analyses conducted.

The OWSA considered $95 \%$ confidence intervals sourced from the original data or pre-specified probabilistic distributions. Standard error was assumed to be $20 \%$ of the mean value, where unreported. A tornado diagram was used to illustrate the uncertainty level of parameters by considering the incremental net monetary benefit (INMB) upper and lower bounds.

Probabilistic sensitivity analysis assigned distributions to model parameters and ran 10,000 simulations to further explore parameter uncertainty. The cohort size, time horizon, cycle length, discount rates, all-cause mortality rates, PTS, lifelong disutility duration, mean drug costs per day, and treatment duration were kept fixed. Dirichlet distributions were assigned to baseline decision-tree data for betrixaban and enoxaparin. Beta distributions were used for the proportion of male patients, event probabilities, utilities, 
Table 3 Scenario analyses

\begin{tabular}{|c|c|}
\hline Parameter & Scenario \\
\hline Discount rate & Discounting costs and outcomes at $0,1.5$, and $6 \%$ per annum \\
\hline Time horizon & Applying shorter time horizons of 3 months, 1 year, 5 years, 10 years, and 15 years \\
\hline $\begin{array}{l}\text { Hazard ratio of death following hospitalization for } \\
\text { an acute medical illness }\end{array}$ & Hazard ratios for death of $1,1.2,1.5$, and 2 \\
\hline Betrixaban efficacy ${ }^{a}$ & $\begin{array}{l}\text { Varying the total number of VTE events, other thrombotic events, and VTE-related deaths } \\
\text { by } 20 \%\end{array}$ \\
\hline Exclusion of asymptomatic DVT events & $\begin{array}{l}\text { Patients experiencing an asymptomatic DVT event reallocated in the decision tree to } \\
\text { experience a non-VTE/non-thrombotic event or a VTE-related death }\end{array}$ \\
\hline Betrixaban and enoxaparin dosing subgroup analysis & $\begin{array}{l}\text { Using only data from patients who received betrixaban } 80 \mathrm{mg} \text { daily compared with enoxa- } \\
\text { parin } 40 \mathrm{mg} \text { daily in the decision tree and for the baseline characteristics }\end{array}$ \\
\hline Inclusion of D-dimer testing for betrixaban patients & $\begin{array}{l}\text { While on treatment in APEX, betrixaban patients aged } \leq 75 \text { years received a single } \\
\text { D-dimer test to establish their VTE-risk factor. From APEX, it was concluded that } 19 \% \\
\text { of all patients would be identified as high risk of VTE by this method and therefore this } \\
\text { proportion of betrixaban patients were assumed to have a D-dimer test }\end{array}$ \\
\hline Treatment duration & $\begin{array}{l}\text { Using the mean, lower and upper bound (of the interquartile range) for the treatment dura- } \\
\text { tion of betrixaban and enoxaparin from APEX rather than the median }\end{array}$ \\
\hline
\end{tabular}

APEX Acute Medically Ill VTE Prevention with Extended Duration Betrixaban, DVT deep-vein thrombosis, VTE venous thromboembolism ${ }^{a}$ Varying the efficacy of betrixaban was performed in the decision tree by raising the incidence of events in relevant arms by $20 \%$, which affected how many patients were filtered through each node of the decision tree

disutilities, percentage of patients with CTEPH receiving surgery, and success rate of CTEPH surgery. Gamma distributions were used for age, number of IS events by severity, hazard ratios, duration of disutilities, costs, and platelet monitoring test frequency per patient.

A cost-effectiveness plane and cost-effectiveness acceptability curve (CEAC) were plotted using the probabilistic results.

\subsubsection{Validation}

The model structure was based on approaches used in previous US cost-effectiveness studies investigating VTE prophylaxis identified by the SLR [33-38]. Clinical data within the model were informed by APEX trial data and SLR-identified published literature. Expert clinical opinion (ATC and SD) informed the model where published literature for resource utilization, costs, and utility inputs were not available, as stated in Online Resource 8 and Online Resource 10 (see the supplementary electronic material). The model was developed internally by two independent health economists, and quality-assessed by a third independent external health economist. Model structure, clinical data inputs, and long-term projections predicted by the model were conceptually validated by two leading clinical experts in VTE prophylaxis (ATC and SD). All feedback obtained by internal and external ratification constructed the final model.

\section{Results}

\subsection{Base Case}

Over a lifetime horizon, the cohort receiving betrixaban accrued 3.240 QALYs at a cost of \$2236 per patient. Patients receiving enoxaparin accrued 3.223 QALYs at a cost of $\$ 3020$. The corresponding incremental cost per QALY gained was dominating in favor of betrixaban, such
Table 4 Base-case results per patient

\begin{tabular}{|c|c|c|c|c|c|c|c|}
\hline \multirow[t]{2}{*}{ Treatment } & \multicolumn{3}{|l|}{ Total } & \multicolumn{3}{|c|}{ Incremental } & \multirow[t]{2}{*}{ ICER (2017 US\$) } \\
\hline & $\begin{array}{l}\text { Costs } \\
\text { (2017 } \\
\text { US\$) }\end{array}$ & LYG & QALYs & $\begin{array}{l}\text { Costs } \\
\text { (2017 } \\
\text { US\$) }\end{array}$ & LYG & QALYs & \\
\hline Enoxaparin & 3020 & 4.765 & 3.223 & - & - & - & \\
\hline Betrixaban & 2236 & 4.780 & 3.240 & -784 & 0.015 & 0.017 & Dominating \\
\hline
\end{tabular}

ICER incremental cost-effectiveness ratio, $L Y G$ life-year gained, $Q A L Y$ quality-adjusted life-year, US\$ United States dollar 
Table 5 Disaggregated base-case results per patient

\begin{tabular}{lll}
\hline & Betrixaban & Enoxaparin \\
\hline $\begin{array}{lll}\text { Decision tree } \\
\quad \text { Prophylaxis cost (2017 US\$) }\end{array}$ & 525 & 233 \\
$\begin{array}{l}\text { Primary event and prophylaxis com- } \\
\quad \text { plications cost (2017 US\$) }\end{array}$ & 672 & 986 \\
LYG & 0.236 & 0.236 \\
QALYs & 0.157 & 0.156 \\
Markov model & & \\
Costs of complications and follow-up & 890 & 1555 \\
$\quad$ for primary events (2017 US\$) & & \\
Recurrent event cost (2017 US\$) & 149 & 246 \\
LYG & 4.544 & 4.529 \\
QALYs & 3.083 & 3.067 \\
Total & & \\
Total costs (2017 US\$) & 2236 & 3020 \\
LYG & 4.780 & 4.765 \\
QALYs & 3.240 & 3.223 \\
\hline
\end{tabular}

$L Y G$ life-year gained, $Q A L Y$ quality-adjusted life-year, US\$ United States dollar

that betrixaban was associated with greater QALYs and fewer costs (Table 4). Table 5 presents the disaggregated results per patient.

\subsection{Sensitivity Analyses}

\subsubsection{Scenario Analyses}

Scenario analyses results, displayed in Table 6, indicate that the model was most sensitive to the time horizon, hazard ratio of death following hospitalization for an acute medical illness, and exclusion of asymptomatic DVT events. Betrixaban dominated enoxaparin in all analyses, with adjustment of betrixaban efficacy having minimal impact on results. The subgroup analysis for betrixaban $80 \mathrm{mg}$ and enoxaparin $40 \mathrm{mg}$ data only showed an increased cost saving of US\$136 and increased gain of 0.004 QALYs for betrixaban $80 \mathrm{mg}$ relative to the base case.

\subsubsection{One-Way Sensitivity Analyses}

Figure 3 illustrates that the two parameters with greatest impact on the INMB were the "no event" utility and the baseline decision-tree distribution. However, betrixaban remained dominant over enoxaparin, and the INMB remained positive, for all analyses at a US\$50,000/QALY willingness-to-pay threshold.

\subsubsection{Probabilistic Sensitivity Analyses}

The mean results of the probabilistic sensitivity analysis (Table 7) were similar to the base case. The cost-effectiveness plane (Fig. 4) and CEAC (Fig. 5) show that betrixaban dominated enoxaparin in the majority $(75.30 \%)$ of simulations and is more likely to be cost-effective than enoxaparin at all willingness-to-pay thresholds considered between US\$0 and US\$100,000. The CEAC shows that the probability of betrixaban being cost-effective at a willingness-to-pay threshold of US\$50,000 was $91.44 \%$.

\section{Discussion}

This analysis compared the costs and QALYs of 36-day betrixaban with 9-day enoxaparin VTE prophylaxis in nonsurgical patients with acute medical illness at high risk of VTE using APEX trial data. Base-case results found that betrixaban dominated enoxaparin, accruing cost savings of US\$784 and increased QALYs of 0.017 per patient over a lifetime horizon. Cost savings were driven by prevention of primary events, recurrent events, and VTE-related complications, which far outweighed the higher treatment cost of betrixaban relative to enoxaparin. QALY gains were driven by reduced risk of VTE-related death and enhanced QoL due to prevention of primary events, recurrent events, and VTE-related complications.

Across sensitivity analyses, betrixaban remained dominating despite significant variations to the time horizon and underlying efficacy of betrixaban, resulting in cost savings and increased QALYs. The OWSA showed greatest variation in the INMB for the "no event" utility and baseline decision-tree distribution parameters, but the INMB remained positive for all analyses at a willingness-to-pay threshold of US\$50,000, indicating the model results are robust to variation in model parameters. Finally, the corresponding probabilistic results indicated a lifetime cost saving of US\$793 with an increase of 0.018 QALYs compared with enoxaparin, similar to deterministic results confirming model robustness.

The subgroup analysis of betrixaban $80 \mathrm{mg}$ and enoxaparin $40 \mathrm{mg}$ data provides strong evidence suggesting the clinical and cost benefits of a 36-day betrixaban regimen compared with 9-day enoxaparin are greater for patients who receive betrixaban $80 \mathrm{mg}$ relative to the base case (whereby patients with severe renal impairment in both study arms or patients who received P-glycoprotein inhibitors in the betrixaban arm received betrixaban $40 \mathrm{mg}$ or enoxaparin $20 \mathrm{mg}$ ).

Statistics show the average length of hospital stay is decreasing in the US [23-26]. As in-hospital VTE prophylaxis duration decreases and becomes increasingly inadequate, the risk of post-discharge VTE rises, increasing the need for VTE prophylaxis extending beyond hospitalization. Additionally, an oral regimen could improve adherence to 
Table 6 Scenario analyses results

\begin{tabular}{|c|c|c|c|c|c|}
\hline Parameter varied & $\begin{array}{l}\text { Betrixaban } \\
\text { total costs } \\
\text { (US\$) }\end{array}$ & $\begin{array}{l}\text { Betrixa- } \\
\text { ban total } \\
\text { QALYs }\end{array}$ & $\begin{array}{l}\text { Incremental costs } \\
\text { (US\$) }\end{array}$ & $\begin{array}{l}\text { Incre- } \\
\text { mental } \\
\text { QALYs }\end{array}$ & ICER \\
\hline Base case & 2236 & 3.240 & -784 & 0.017 & Dominating \\
\hline Discount rate: $0 \%$ & 2372 & 3.615 & -877 & 0.020 & Dominating \\
\hline Discount rate: $1.5 \%$ & 2300 & 3.417 & -828 & 0.018 & Dominating \\
\hline Discount rate: $6 \%$ & 2128 & 2.941 & -710 & 0.015 & Dominating \\
\hline Time horizon: 3 months & 1197 & 0.157 & -22 & 0.001 & Dominating \\
\hline Time horizon: 1 year & 1310 & 0.608 & -128 & 0.003 & Dominating \\
\hline Time horizon: 5 years & 1859 & 2.229 & -531 & 0.011 & Dominating \\
\hline Time horizon: 10 years & 2163 & 3.027 & -737 & 0.016 & Dominating \\
\hline $\begin{array}{l}\text { Hazard ratio of death following hospitalization for an acute medical } \\
\text { illness: } 1\end{array}$ & 3175 & 5.946 & -1419 & 0.032 & Dominating \\
\hline $\begin{array}{l}\text { Hazard ratio of death following hospitalization for an acute medical } \\
\text { illness: } 1.2\end{array}$ & 2577 & 4.231 & -1016 & 0.023 & Dominating \\
\hline $\begin{array}{l}\text { Hazard ratio of death following hospitalization for an acute medical } \\
\text { illness: } 1.5\end{array}$ & 2042 & 2.666 & -650 & 0.014 & Dominating \\
\hline $\begin{array}{l}\text { Hazard ratio of death following hospitalization for an acute medical } \\
\text { illness: } 2\end{array}$ & 1656 & 1.482 & -379 & 0.008 & Dominating \\
\hline Betrixaban efficacy: $20 \%$ more VTE events & 2446 & 3.235 & -574 & 0.012 & Dominating \\
\hline Betrixaban efficacy: $20 \%$ more other thrombotic events & 2327 & 3.236 & -692 & 0.013 & Dominating \\
\hline Betrixaban efficacy: $20 \%$ more fatal VTE events & 2235 & 3.238 & -785 & 0.015 & Dominating \\
\hline Exclusion of asymptomatic DVT events & 1467 & 3.252 & -578 & 0.015 & Dominating \\
\hline $\begin{array}{l}\text { Betrixaban and enoxaparin dosing subgroup analysis (patients } \\
\text { receiving betrixaban } 80 \mathrm{mg} \text { or enoxaparin } 40 \mathrm{mg} \text { ) }\end{array}$ & 2101 & 3.304 & -920 & 0.021 & Dominating \\
\hline $\begin{array}{l}\text { Treatment duration (mean): } 33 \text { days for betrixaban and } 10 \text { days for } \\
\text { enoxaparin }\end{array}$ & 2,191 & 3.240 & -843 & 0.017 & Dominating \\
\hline $\begin{array}{l}\text { Treatment duration (lower bound of the interquartile range): } 34 \text { days } \\
\text { for betrixaban and } 7 \text { days for enoxaparin }\end{array}$ & 2206 & 3.240 & -786 & 0.017 & Dominating \\
\hline $\begin{array}{l}\text { Treatment duration (upper bound of the interquartile range): } 39 \text { days } \\
\text { for betrixaban and } 13 \text { days for enoxaparin }\end{array}$ & 2281 & 3.240 & -796 & 0.017 & Dominating \\
\hline Inclusion of D-dimer tests for $19 \%$ of betrixaban patients ${ }^{a}$ & 2241 & 3.240 & -780 & 0.017 & Dominating \\
\hline
\end{tabular}

APEX Acute Medically Ill VTE Prevention with Extended Duration Betrixaban, DVT deep-vein thrombosis, ICER incremental cost-effectiveness ratio, $Q A L Y$ quality-adjusted life-year, US\$ United States dollar, VTE venous thromboembolism

${ }^{a} \mathrm{D}$-dimer testing was carried out in the APEX study, but is not usual in clinical practice. It has been assumed that $50 \%$ of patients aged $\leq 75$ years would be identified as at-risk of VTE by a single D-dimer test whilst receiving betrixaban treatment. In APEX, the proportion of patients aged $\leq 75$ years was $38 \%$; hence $19 \%$ of all betrixaban patients were assumed to have a D-dimer test

therapy as studies show that administration routes have an impact on patient preferences and adherence, with patients more likely to comply with oral regimens compared with injections [55-57]; such regimens avoid the issues associated with injection regimens, including patient discomfort with self-injections, problems with adherence to therapy, and costs incurred due to nurse administration of the medication.

Several relevant US-perspective cost-effectiveness studies were identified, although these were based on short-term, inhospital VTE prophylaxis. Two studies investigated the costeffectiveness of VTE prophylaxis with enoxaparin, UFH, and no prophylaxis in hospitalized medical patients [33, 34]. One study compared the cost-effectiveness of LMWH against no prophylaxis [37], one compared enoxaparin with no prophylaxis [36], one compared enoxaparin with UFH [35], and one compared dalteparin with UFH [58]. Another study compared ultrasound screening with a DVT prevention program in patients receiving LMWH [38]. Four of the studies $[33-35,58]$ used a payer perspective, and six studies used a decision tree, a Markov model, or a combination of both to evaluate cost-effectiveness [33-38]. Of the studies incorporating a Markov model, two studies used a lifetime horizon and a discount rate of $3 \%$ per annum $[37,38]$ and the other used a 2-year time horizon (discount rate not reported) [34]. As none of the previous cost-effectiveness studies involved betrixaban, no direct comparison between results can be made. However, one study identified that dalteparin 


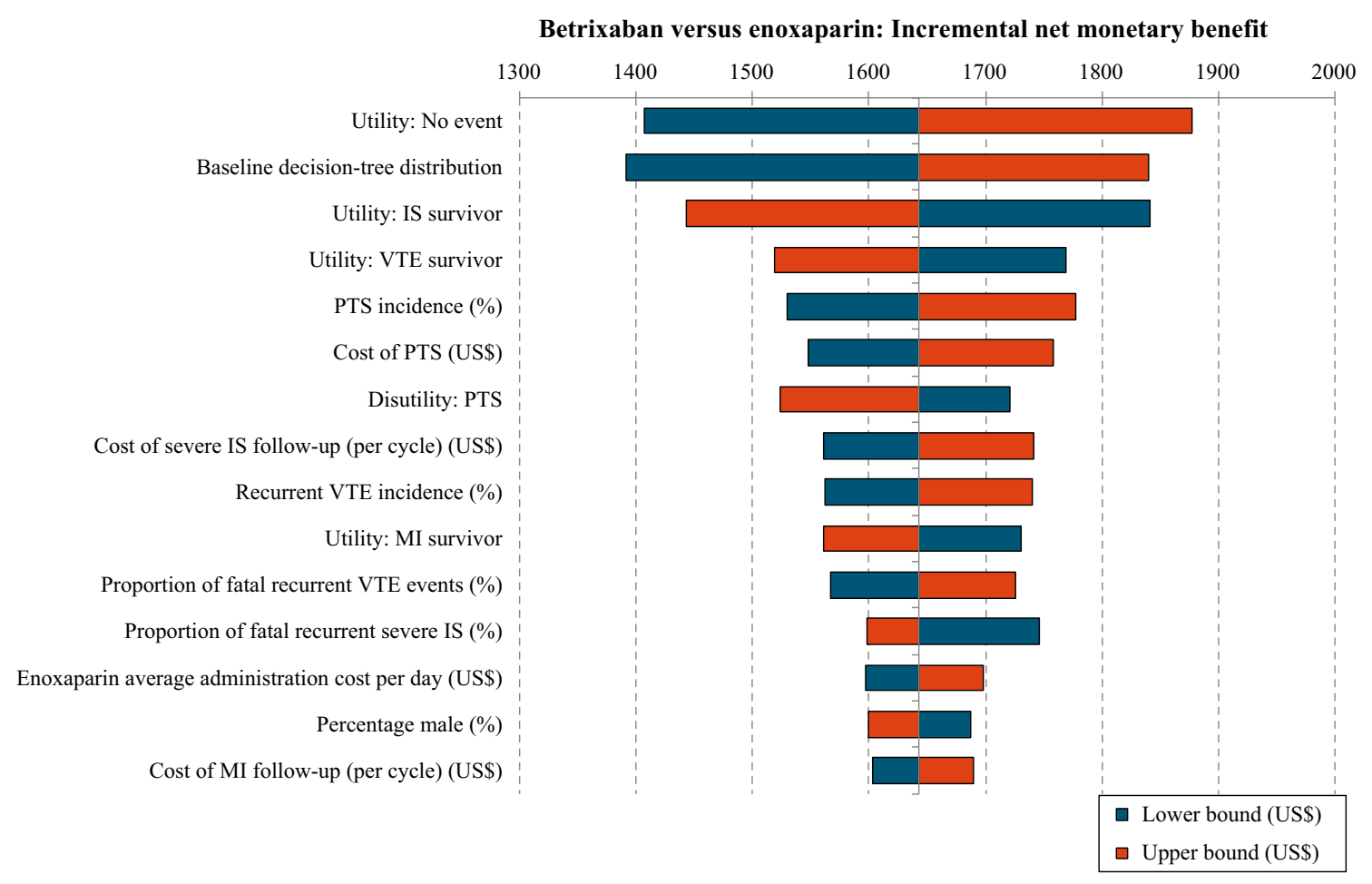

Fig. 3 Tornado diagram of the 15 most sensitive parameters. NMB assigns a cost value to health benefits and compares this against the cost of treatment using the formula $\mathrm{NMB}=(\mathrm{QALYs}) \times(\mathrm{WTP})-$ $C$, where $C$ is the cost of treatment. A higher NMB corresponds to a more cost-effective strategy; hence the positive INMB found by comparing prophylaxis with betrixaban to enoxaparin indicated that

dominated UFH and three studies found that enoxaparin dominated UFH [33-35, 58].

Six studies did not report or determine total QALYs gained for patients receiving enoxaparin or other LMWH [33-37, 58]. One study estimated critically ill patients receiving an unspecified LMWH accrued 5.93 QALYs, compared with 3.22 reported herein [38]. However, the analyses consider significantly different scenarios, making direct comparison infeasible: different populations and eligibility criteria, different baseline ages (65 vs 76), different settings (intensive care vs ward), different baseline utility sources (mechanical ventilation vs acute medically ill patients), and different treatment durations (22 vs 9 days). Additionally, the intervention received was unspecified in betrixaban was a more cost-effective strategy. INMB incremental net monetary benefit, $I S$ ischemic stroke, $M I$ myocardial infarction, $N M B$ net monetary benefit, PTS post-thrombotic syndrome, $Q A L Y$ quality-adjusted life-year, US\$ United States dollar, VTE venous thromboembolism, WTP willingness-to-pay

the study, preventing comparability with the QALY estimate for enoxaparin patients.

This analysis has a number of strengths. The model structure captured short- and long-term events, and was aligned to that adopted by other cost-effectiveness analyses considering VTE prophylaxis [33-38]. Clinical effectiveness data are based on a large well-conducted RCT comparing betrixaban with enoxaparin. Published literature provided sufficient data to parameterize costs and utilities. Results were validated with two leading experts in VTE prophylaxis (ATC and SD).

The main limitation of the analysis was the necessity of using published literature to inform rates of recurrence and VTE-related complications, since APEX only reported data through to day 77. It is unclear how generalizable these reported data are to the nonsurgical medically ill population;
Table 7 Disaggregated probabilistic sensitivity analysis results

\begin{tabular}{lllllll}
\hline Treatment & \multicolumn{2}{l}{ Total } & & & Incremental & ICER (2017 US\$) \\
\cline { 2 - 3 } & $\begin{array}{l}\text { Costs }(2017 \\
\text { US\$) }\end{array}$ & QALYs & & Costs (2017 US\$) & QALYs & \\
\hline Enoxaparin & 3042 & 3.228 & & - & - & - \\
Betrixaban & 2249 & 3.245 & & -793 & 0.018 & Dominating \\
\hline
\end{tabular}

ICER incremental cost-effectiveness ratio, $Q A L Y$ quality-adjusted life-year, US\$ United States dollar 


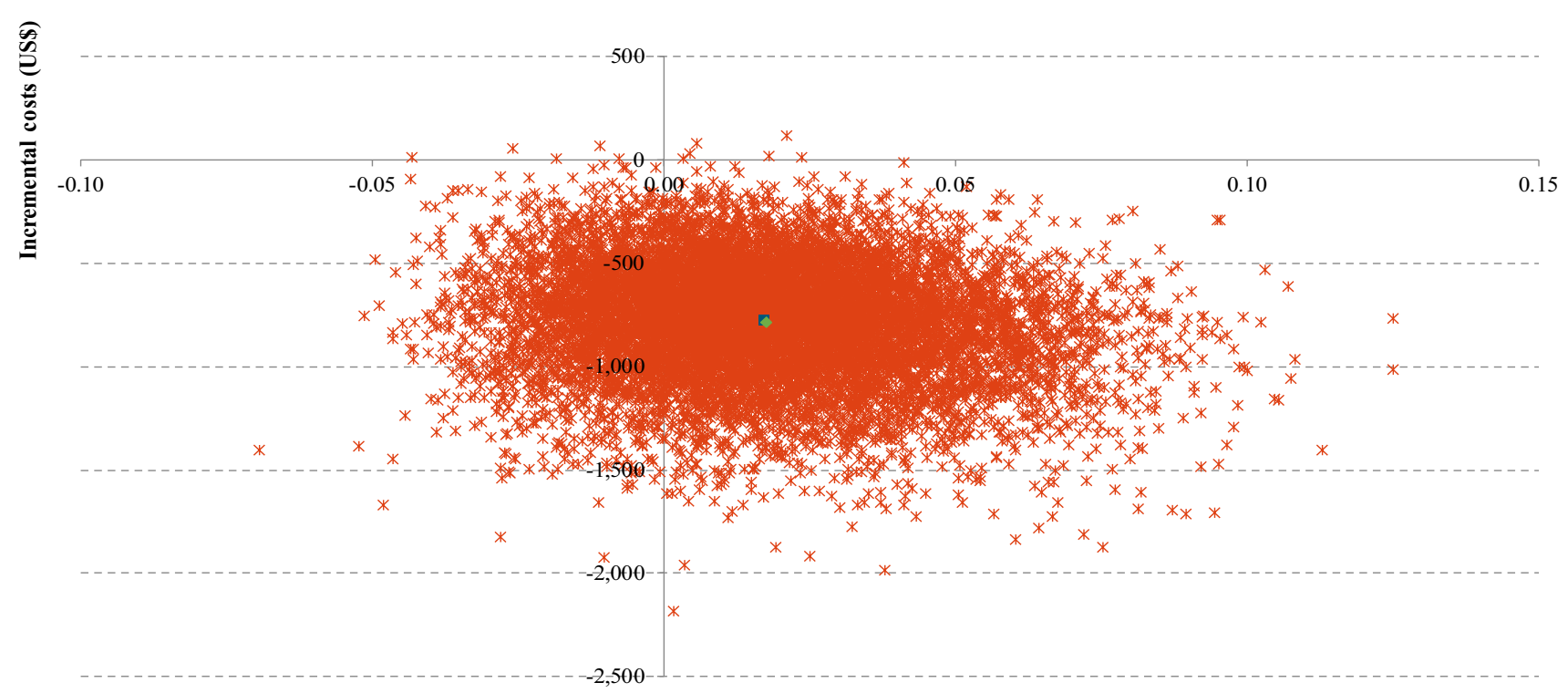

Incremental QALYs

* Betrixaban vs. enoxaparin: individual results $\quad$ Deterministic mean Probabilistic mean

Fig. 4 Incremental cost-effectiveness plane. $Q A L Y$ quality-adjusted life-year, US\$ United States dollar

indeed, rates may be under- or over-estimated for this analysis. Nevertheless, extensive sensitivity analyses were performed, all of which found that betrixaban dominated enoxaparin.
Additionally, paucity of clinical trial data comparing VTE prophylaxis through post-hospital discharge with betrixaban versus enoxaparin in the target population limited this analysis. The EXCLAIM, MAGELLAN, and ADOPT

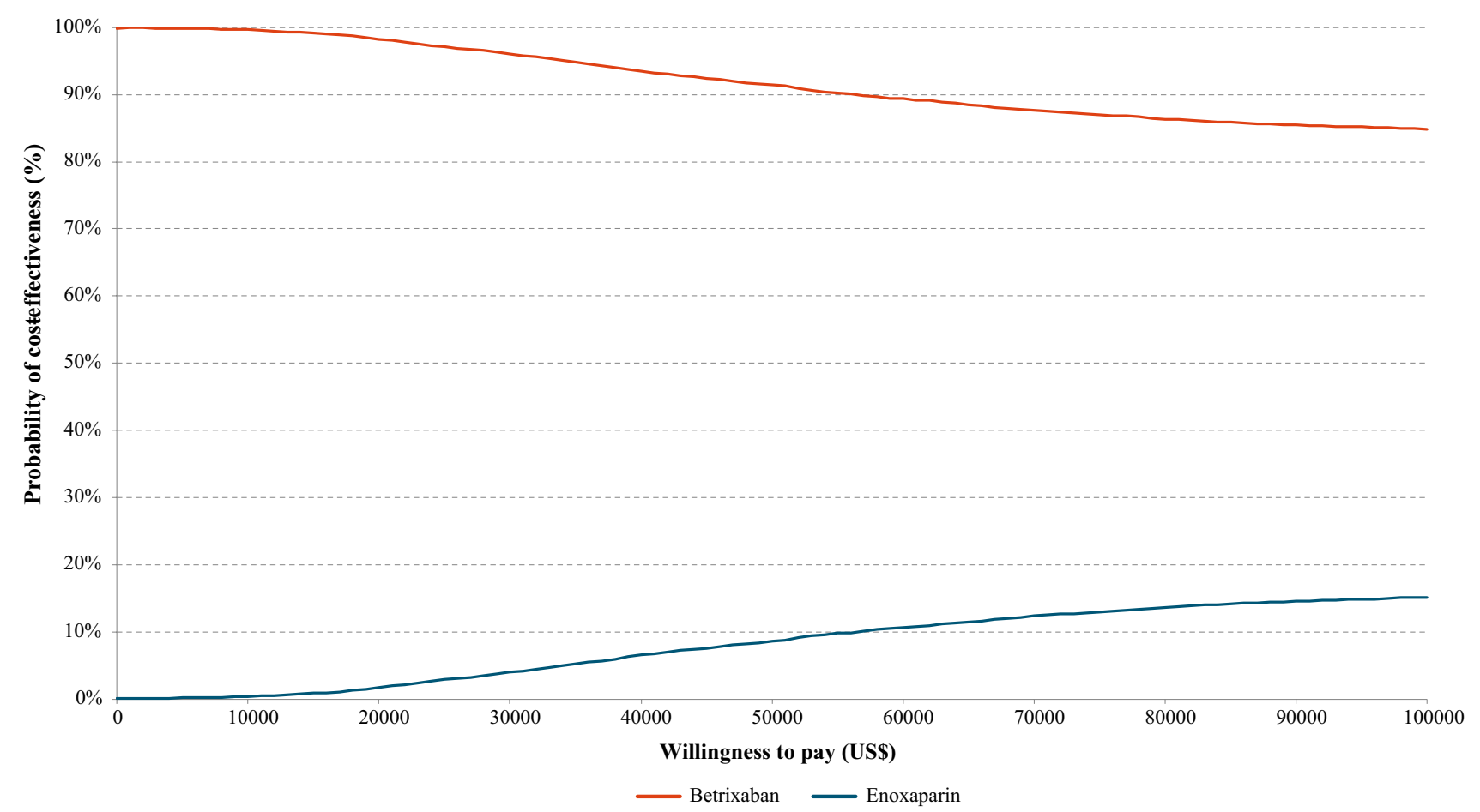

Fig. 5 Cost-effectiveness acceptability curve. US\$ United States dollar 
trials, which respectively compared through post-discharge regimens of enoxaparin, rivaroxaban, and apixaban, with in-hospital enoxaparin, all found that longer prophylaxis reduced VTE risk, but increased MB, making these regimens unsuitable comparators [16-18]. APEX analyzed prophylaxis with betrixaban through post-discharge compared with enoxaparin in-hospital and reported promising results [30]. As the pivotal study investigating betrixaban through post-discharge, it was the only source of patientlevel data for betrixaban available for this analysis.

Future research could expand the scope of this analysis to estimate the cost-effectiveness of betrixaban with other current prophylactic treatments; this might generalize this analysis to other populations at risk of VTE and broaden the understanding of clinical and economic benefits of VTE prophylaxis from hospitalization through post-discharge.

\section{Conclusion}

Driven by improved clinical outcomes in APEX, betrixaban was associated with improvements in survival and QALYs, and was less costly than enoxaparin. This analysis suggests that betrixaban is a cost-effective alternative to enoxaparin for nonsurgical patients with acute medical illness at risk of VTE and could lead to significant savings for payers in the US, with a mean saving of US\$784 per patient and an improvement in a patient's QoL of 0.017 QALYs.

Acknowledgments The authors thank Aimee North for her writing and editing assistance (FIECON Ltd). Editorial support was provided by Catherine Stanton of CMC AFFINITY, a division of Complete Medical Communications Ltd, Glasgow, UK, funded by FIECON Ltd.

Author Contributions HG, VL, MF, WRN, and AC were involved in the design and execution of the analysis. All authors were involved in the interpretation of the results and the drafting and revision of this manuscript, and provided final approval of the version to be published. All authors vouch for the accuracy of the content included in the full manuscript.

\section{Compliance with Ethical Standards}

Conflict of interest HG, VL, and MF are employees of FIECON Ltd, a health-economics outcomes research agency, which performed the analyses presented in the manuscript, funded by Portola Pharmaceuticals, Inc. WRN and IB are employees of Portola Pharmaceuticals, Inc. SD has received consulting fees or honoraria, fees for provision of medicines, equipment, or administrative support, and payment for lectures from Portola Pharmaceuticals, Inc, Pfizer, Janssen and BMS. SD has received support for travel to meetings from Portola Pharmaceuticals, Inc and fees for expert testimony from Janssen. ATC has received consulting fees, research support, and honoraria from AbbVie, ACI Clinical, Aspen, Bayer, Boehringer Ingelheim, Bristol-Myers Squibb, Boston Scientific, CSL Behring, Daiichi-Sankyo, GlaxoSmithKline, GLG, Guidepoint Global, Johnson and Johnson, Leo Pharma, Med- scape, McKinsey, Navigant, ONO, Pfizer, Portola Pharmaceuticals, Inc, Sanofi, Takeda, Temasek Capital, and TRN.

Funding This analysis was supported by Portola Pharmaceuticals, Inc.

Research involving human participants and/or animals For this type of study, formal consent is not required.

Data Sharing Statement The datasets generated during and/or analyzed during the current study are available from the corresponding author on reasonable request.

Open Access This article is distributed under the terms of the Creative Commons Attribution-NonCommercial 4.0 International License (http://creativecommons.org/licenses/by-nc/4.0/), which permits any noncommercial use, distribution, and reproduction in any medium, provided you give appropriate credit to the original author(s) and the source, provide a link to the Creative Commons license, and indicate if changes were made.

\section{References}

1. Wendelboe AM, Raskob GE. Global burden of thrombosis: epidemiologic aspects. Circ Res. 2016;118:1340-7.

2. Grosse SD, Nelson RE, Nyarko KA, Richardson LC, Raskob GE. The economic burden of incident venous thromboembolism in the United States: a review of estimated attributable healthcare costs. Thromb Res. 2016;137:3-10.

3. Beckman MG, Hooper WC, Critchley SE, Ortel TL. Venous thromboembolism: a public health concern. Am J Prev Med. 2010;38:S495-501.

4. Cohen AT, Gitt AK, Bauersachs R, Fronk E-M, Laeis P, Mismetti $\mathrm{P}$, et al. The management of acute venous thromboembolism in clinical practice. Results from the European PREFER in VTE Registry. Thromb Haemost. 2017;117:1326-37.

5. Kachroo S, Boyd D, Bookhart BK, LaMori J, Schein JR, Rosenberg DJ, et al. Quality of life and economic costs associated with postthrombotic syndrome. Am J Health Syst Pharm. 2012;69:567-72.

6. Jha AK, Larizgoitia I, Audera-Lopez C, Prasopa-Plaizier N, Waters H, Bates DW. The global burden of unsafe medical care: analytic modelling of observational studies. BMJ Qual Saf. 2013;22:809-15.

7. Raskob GE, Angchaisuksiri P, Blanco AN, Buller H, Gallus A, Hunt BJ, et al. Thrombosis: a major contributor to global disease burden. Arterioscler Thromb Vasc Biol. 2014;34:2363-71.

8. Anderson FA, Zayaruzny M, Heit JA, Fidan D, Cohen AT. Estimated annual numbers of US acute-care hospital patients at risk for venous thromboembolism. Am J Hematol. 2007;82:777-82.

9. Mehta KD, Patel S, Patel K, Wang H, Parikh RA, Smith RE. Trends of inpatient venous thromboembolism in United States before and after Surgeon General's Call to Action. Blood. 2016;128:1177.

10. Amin AN, Varker H, Princic N, Lin J, Thompson S, Johnston S. Duration of venous thromboembolism risk across a continuum in medically ill hospitalized patients. J Hosp Med. 2012;7:231-8.

11. Spencer FA, Lessard D, Emery C, Reed G, Goldberg RJ. Venous thromboembolism in the outpatient setting. Arch Intern Med. 2007; 167:1471-5.

12. Spyropoulos AC, Hussein M, Lin J, Battleman D. Rates of venous thromboembolism occurrence in medical patients among the insured population. Thromb Haemost. 2009;102:951-7.

13. Amin AN, Lin J, Thompson S, Wiederkehr D. Real-world rates of in-hospital and postdischarge deep-vein thrombosis and 
pulmonary embolism in at-risk medical patients in the United States. Clin Appl Thromb Hemost. 2011;17:611-9.

14. Spyropoulos AC, Anderson FA, FitzGerald G, Decousus H, Pini M, Chong BH, et al. Predictive and associative models to identify hospitalized medical patients at risk for VTE. Chest. 2011;140:706-14.

15. Pendergraft T, Atwood M, Liu X, Phatak H, Liu LZ, Oster G. Cost of venous thromboembolism in hospitalized medically ill patients. Am J Health Syst Pharm. 2013;70:1681-7.

16. Cohen AT, Spiro TE, Büller HR, Haskell L, Hu D, Hull R, et al. Rivaroxaban for thromboprophylaxis in acutely ill medical patients. N Engl J Med. 2013;368:513-23.

17. Goldhaber SZ, Leizorovicz A, Kakkar AK, Haas SK, Merli G, Knabb RM, et al. Apixaban versus enoxaparin for thromboprophylaxis in medically ill patients. N Engl J Med. 2011;365:2167-77.

18. Hull RD, Schellong SM, Tapson VF, Monreal M, Samama MM, Nicol P, et al. Extended-duration venous thromboembolism prophylaxis in acutely ill medical patients with recently reduced mobility: a randomized trial. Ann Intern Med. 2010;153:8-18.

19. Kahn SR, Lim W, Dunn AS, Cushman M, Dentali F, Akl EA, et al. Prevention of VTE in nonsurgical patients: antithrombotic Therapy and Prevention of Thrombosis, 9th ed: American College of Chest Physicians Evidence-Based Clinical Practice Guidelines. Chest. 2012;141:e195S-226S.

20. Qaseem A. Venous thromboembolism prophylaxis in hospitalized patients: a clinical practice guideline from the American College of Physicians. Ann Intern Med. 2011;155:625.

21. Chan NC, Bhagirath V, Eikelboom JW. Profile of betrixaban and its potential in the prevention and treatment of venous thromboembolism. Vasc Health Risk Manag. 2015;11:343-51.

22. Hutchaleelaha A, Ye C, Song Y, Lorenz T, Gretler D, Lambing JL. Metabolism and disposition of betrixaban and its lack of interaction with major CYP enzymes. Blood. 2012;120:2266.

23. Weiss AJ, Elixhauser A, for Agency for Healthcare Research and Quality. Overview of hospital stays in the United States, 2012. 2014. https://www.hcup-us.ahrq.gov/reports/statbriefs/sb180 -Hospitalizations-United-States-2012.pdf. Accessed 20 Mar 2018.

24. Organisation for Economic Co-operation and Development. Health at a glance 2017: OECD indicators. 2017. https://www. oecd-ilibrary.org/docserver/health_glance-2017-en.pdf?expir es $=1536312324 \& \mathrm{id}=\mathrm{id} \&$ accname $=$ guest $\&$ checksum $=9 \mathrm{~A} 218$ 3B01DA4247F63CA207618BB50BB. Accessed 20 Mar 2018.

25. US Department of Health and Human Services. CMS Statistics. 2015. https://www.cms.gov/Research-Statistics-Data-and-Syste $\mathrm{ms} /$ Statistics-Trends-and-Reports/CMS-Statistics-ReferenceBooklet/Downloads/2015CMSStatistics.pdf. Accessed 24 May 2018.

26. US Department of Health and Human Services. CMS Statistics. 2016. https://www.cms.gov/Research-Statistics-Data-and-Syste ms/Statistics-Trends-and-Reports/CMS-Statistics-ReferenceBooklet/Downloads/2016_CMS_Stats.pdf. Accessed 24 May 2018.

27. Food and Drug Administration. FDA approved betrixaban (BEVYXXA, Portola) for the prophylaxis of venous thromboembolism (VTE) in adult patients. https://www.fda.gov/Drugs/Informatio nOnDrugs/ApprovedDrugs/ucm564422.htm. Accessed 20 Mar 2018.

28. Food and Drug Administration. BEVYXXA ${ }^{\mathrm{TM}}$ Highlights of prescribing information. 2017. https://www.accessdata.fda.gov/drugs atfda_docs/label/2017/208383s000lbl.pdf. Accessed Mar 2018.

29. Gibson CM, Nafee T, Yee MK, Chi G, Korjian S, Daaboul Y, et al. Symptomatic event reduction with extended-duration betrixaban in acute medically ill hospitalized patients. Am Heart J. 2018;198:84-90.
30. Cohen AT, Harrington RA, Goldhaber SZ, Hull RD, Wiens BL, Gold A, et al. Extended thromboprophylaxis with betrixaban in acutely ill medical patients. N Engl J Med. 2016;375:534-44.

31. Gibson, CM H RA, Goldhaber, SZ H RD, Hernandez, AF W BL, Gold, A C AT. Gibson CM, Harrington RA, et al. Efficacy and safety of betrixaban for extended duration thromboprophylaxis among acutely ill medical patients, ISTH 2016. 2016. http://www. clinicaltrialresults.org/Poster_ISTH_2016_APEX.pdf. Accessed Mar 2018.

32. Cohen AT, Harrington RA, Goldhaber SZ, Hull RD, Wiens BL, Gold A, et al. Extended thromboprophylaxis with betrixaban in acutely ill medical patients. N Engl J Med. 2016;375:534-44. https://doi.org/10.1056/NEJMoa1601747 (supplementary material).

33. McGarry LJ, Thompson D, Weinstein MC, Goldhaber SZ. Cost effectiveness of thromboprophylaxis with a low-molecular-weight heparin versus unfractionated heparin in acutely ill medical inpatients (Structured abstract). Am J Manag Care. 2004;10:632-42.

34. Deitelzweig SB, Becker R, Lin J, Benner J. Comparison of the two-year outcomes and costs of prophylaxis in medical patients at risk of venous thromboembolism (Structured abstract). Thromb Haemost. 2008;100:810-20.

35. Leykum L, Pugh J, Diuguid D, Papadopoulos K. Cost utility of substituting enoxaparin for unfractionated heparin for prophylaxis of venous thrombosis in the hospitalized medical patient (Structured abstract). J Hosp Med. 2006;1:168-76.

36. Le P, Martinez KA, Pappas MA, Rothberg MB. A decision model to estimate a risk threshold for venous thromboembolism prophylaxis in hospitalized medical patients. J Thromb Haemost. 2017;15:1132-41.

37. Le PH, Rothberg MB. Determining the threshold for venous thromboembolism prophylaxis for hospitalized medical patients: a cost-effectiveness analysis. J Gen Intern Med. 2016;31:S180.

38. Sud S, Mittmann N, Cook DJ, Geerts W, Chan B, Dodek P, et al. Screening and prevention of venous thromboembolism in critically ill patients: a decision analysis and economic evaluation. Am J Respir Crit Care Med. 2011;184:1289-98.

39. Arepally GM. Heparin-induced thrombocytopenia. Blood. 2017;129:2864-72.

40. Lansberg MG, O’Donnell MJ, Khatri P, Lang ES, Nguyen-Huynh $\mathrm{MN}$, Schwartz NE, et al. Antithrombotic and thrombolytic therapy for ischemic stroke. Chest. 2012;141:e601S-36S.

41. Lee WC, Christensen MC, Joshi AV, Pashos CL. Long-term cost of stroke subtypes among Medicare beneficiaries. CED. 2007;23:57-65.

42. Fogelholm R, Murros K, Rissanen A, Avikainen S. Long term survival after primary intracerebral haemorrhage: a retrospective population based study. J Neurol Neurosurg Psychiatry. 2005;76:1534-8.

43. Petty GW, Brown RD, Whisnant JP, Sicks JD, O'Fallon WM, Wiebers DO. Ischemic stroke subtypes: a population-based study of functional outcome, survival, and recurrence. Stroke. 2000;31:1062-8.

44. World Health Organisation. WHO Guide to Cost-effectiveness analysis. 2003. http://www.who.int/choice/publications/p_2003_ generalised_cea.pdf. Accessed Mar 2017.

45. Gibson CM, Korjian S, Chi G, Daaboul Y, Jain P, Arbetter D, et al. Comparison of fatal or irreversible events with extended duration betrixaban versus standard dose enoxaparin in acutely ill medical patients: an APEX trial substudy. J Am Heart Assoc. 2017. https ://www.ncbi.nlm.nih.gov/pmc/articles/PMC5586307/. Accessed 7 Sept 2018.

46. Arias E, Heron M, Xu J. United States life tables, 2013. Natl Vital Stat Rep. 2017;66:1-64. 
47. Alter DA, Ko DT, Tu JV, Stukel TA, Lee DS, Laupacis A, et al. The average lifespan of patients discharged from hospital with heart failure. J Gen Intern Med. 2012;27:1171-9.

48. United States Department of Labor. CPI medical inflation rates. 2018. https://data.bls.gov/timeseries/CUUR0000SAM?outpu t_view=pct_12mths. Accessed Mar 2018.

49. Utne KK, Tavoly M, Wik HS, Jelsness-Jørgensen LP, Holst R, Sandset PM, et al. Health-related quality of life after deep vein thrombosis. Springerplus. 2016;5:1278.

50. Tavoly M, Utne KK, Jelsness-Jørgensen L-P, Wik HS, Klok FA, Sandset PM, et al. Health-related quality of life after pulmonary embolism: a cross-sectional study. BMJ Open. 2016;6:e013086.

51. NICE. Apixaban (Eliquis ${ }^{\circledR}$ ) for the prevention of stroke and systemic embolism in people with non-valvular atrial fibrillation: single technology appraisal (STA). 2012. https://www.nice.org.uk/ guidance/ta275/documents/stroke-and-systemic-embolism-preve ntion-nonvalvular-atrial-fibrillation-apixaban-bristolmyers-squib b-and-pfizer2. Accessed Mar 2018.

52. NICE. Single technology appraisal of rivaroxaban (Xarelto ${ }^{\circledR}$ ). 2011. Available from: https://www.nice.org.uk/guidance/ta256/ documents/atrial-fibrillation-stroke-prevention-rivaroxaban-bayer 4. Accessed Mar 2018.

53. Lanitis T, Leipold R, Hamilton M, Rublee D, Quon P, Browne C, et al. Cost-effectiveness of apixaban versus low molecular weight heparin/vitamin $\mathrm{k}$ antagonist for the treatment of venous thromboembolism and the prevention of recurrences. BMC Health Serv Res. 2017;17:74.

54. NICE. Clinical Guideline. Venous thromboembolism in over $16 \mathrm{~s}$ : reducing the risk of hospital-acquired deep vein thrombosis or pulmonary embolism (Update). 2017. https://www.nice.org.uk/ guidance/indevelopment/gid-cgwave0795/consultation/html-conte nt-2. Accessed Mar 2018.

55. Popoola VO, Tavakoli F, Lau BD, Lankiewicz M, Ross P, Kraus P, et al. Exploring the impact of route of administration on medication acceptance in hospitalized patients: implications for venous thromboembolism prevention. Thromb Res. 2017;160:109-13.

56. Popoola VO, Lau BD, Tan E, Shaffer DL, Kraus PS, Farrow NE, et al. Nonadministration of medication doses for venous thromboembolism prophylaxis in a cohort of hospitalized patients. Am J Health Syst Pharm. 2018;75:392-7.

57. Sevilla-Cazes J, Finkleman BS, Chen J, Brensinger CM, Epstein AE, Streiff MB, et al. Association between patient-reported medication adherence and anticoagulation control. Am J Med. 2017;130(1092-1098):e2.

58. Fowler RA, Mittmann N, Geerts W, Heels-Ansdell D, Gould MK, Guyatt $\mathrm{G}$, et al. Cost-effectiveness of dalteparin vs unfractionated heparin for the prevention of venous thromboembolism in critically ill patients. JAMA. 2014;312:2135-45. 